\title{
Knowledge and perceptions of the risks of Non-steroidal Anti-Inflammatory Drugs among orthopedic patients in Thailand
}

\author{
Pacharaporn Phueanpinit $^{1}$, Juraporn Pongwecharak ${ }^{2}$, Janet Krska ${ }^{3}$, and Narumol \\ Jarernsiripornkul ${ }^{1}$ \\ ${ }^{1}$ Faculty of Pharmaceutical Sciences, Khon Kaen University, Khon Kaen, Thailand. \\ ${ }^{2}$ Faculty of Pharmacy, Thammasat University, Pathumthani, Thailand. \\ ${ }^{3}$ Medway School of Pharmacy, Universities of Greenwich and Kent, Kent, UK.
}

Corresponding Author at:

Narumol Jarernsiripornkul

Department of Clinical Pharmacy

Faculty of Pharmaceutical Sciences, Khon Kaen University

Khon Kaen, 40002, Thailand

E-mail: narumol@kku.ac.th

Tel.: +66-4334-8353

Fax: +66-4320-2379 


\begin{abstract}
Background There is a high incidence of adverse effects from non-steroidal anti-inflammatory drugs (NSAIDs) in Thailand, but patients' perceptions and knowledge of NSAID risks is unknown. Objective This study aims to assess patients' perceptions and knowledge of NSAID risks and factors affecting them.

Setting University hospital in North-East of Thailand

Method A Cross-sectional study conducted over 4 months, using a self-administered questionnaire. Patients prescribed NSAIDs at least one month duration from orthopaedic clinic were recruited by using systematic random sampling.

Main outcome measure Patients' perceptions on NSAID risks, knowledge on risk factors, and their associated factors.

Results A total of 474 questionnaires were assessed. Overall perceptions of risks was low (scoring below five on a $0-10$ visual analogue scale), with risks associated with the renal system scoring highest. Perceived risk of gastrointestinal problems differed between patients using non-selective and selective NSAIDs $(3.47 \pm 2.75$ vs $2.06 \pm 2.98 ; \mathrm{P}<0.001)$. Receiving side effect information from a health professional was associated with higher risk perception. Most patients (80\%) identified high doses, renal disease and gastrointestinal ulcer increased risks of NSAIDs, but fewer than half recognized that use in the elderly, multiple NSAID use, drinking, hypertension and cardiovascular disease also increased risk of adverse events. Having underlying diseases and receiving side effect information were associated with 1.6-2.0 fold increased knowledge of NSAID risks.
\end{abstract}


Conclusion Perceptions and knowledge concerning NSAID risks was generally low in Thai patients, but higher in those who had received side effect information. Risk-related information should be widely provided, especially in high-risk patients.

\section{Impact of findings on practice}

- Lack of awareness of risk of NSAIDs among Thai patients may lead to inappropriate use of these medicines, therefore health professionals should provide more information about their risks.

- Older patients, those with low educational level and those who had not been given any side effect information had poorest perception and knowledge about NSAID risk, therefore these groups should be specifically targeted.

Keywords: Perception, Knowledge, Non-steroidal anti-inflammatory drugs, Risk factors, Thailand 


\section{Introduction}

Non-steroidal anti-inflammatory drugs (NSAIDs) are widely used and effective for pain and inflammation, but carry a high risk of side effects [1]. Despite this, they are frequently prescribed to patients with underlying factors increasing risk, such as the elderly, and those with comorbidities or multiple drug use [2]. Moreover studies in a range of countries suggest that patients have little awareness of the risk of these medicines [3-10]. In one study only a third of Turkish patients with osteoarthritis were aware of side effects of NSAIDs, with $85.4 \%$ of these identifying only gastrointestinal risks [5]. Almost half the patients surveyed in a Malaysian rheumatology clinic had no knowledge of NSAID side effects, while patients in a Danish rheumatology clinic showed lack of awareness of underlying factors which can increase risks of side effects [6]. However we found no studies exploring knowledge of NSAID risks among orthopaedic patients. Previous studies from several countries also suggest frequent inappropriate use of over the counter NSAIDs, as well as poor knowledge of risks associated with these agents $[4,8,12]$. One such study, conducted in Thailand, found that NSAID use was inversely related to knowledge about NSAIDs but positively associated with obtaining analgesics from community pharmacies [12].

NSAID use in Thailand is associated with adverse events, as elsewhere. A retrospective study involving 12,591 NSAID prescriptions from 1,030 patients found a total of 78 gastrointestinal events and 49 cardiovascular events [13]. Over the period 1984-2014, analgesic drugs, particularly NSAIDs, were the second most frequently cited drugs in spontaneous adverse drug reaction (ADR) reports in Thailand [14]. Meanwhile, only gastrointestinal side effects were often concerned and identified by patients, but other complications were less concerned $[5,15]$.

Awareness of the potential side effects of NSAIDs and factors increasing their risk is important, to ensure that patients achieve optimum benefit with minimal adverse events. The 
provision of information is thus key when prescribing and supplying these drugs. In many countries, written information is provided with all medicines, but some studies suggest that this does not necessarily translate into increased awareness of potential risks [16, 17]. For many people, health professionals are the main source of information about medicines [18-23], particularly in countries where written information is less freely available, such as Thailand [24]. We have previously shown that pharmacists and physicians play a major role in providing medicines safety information to Thai patients prescribed NSAIDs [25]. However, relatively little is known about Thai patients' perceptions and knowledge of NSAID risks.

\section{Aims of the study}

In this study, we aim to determine patients' perceptions and knowledge of the risks of NSAIDs and factors affecting them.

\section{Ethical approval}

The study was approved by the Ethics Committee for Human research, Khon Kaen University. Reference number HE551130.

\section{Methods}

\section{Study design and setting}

This cross-sectional study was conducted in an 800-bed university hospital, Khon Kaen, Thailand between February 2013 and May 2013. It involved patients visiting out-patient orthopaedic clinics during the study period, and using prescribed NSAIDs for at least one month. A systematic random sampling method was used to select the patients, excluding patients below 18 years of age, those unable to complete the questionnaire themselves or without support to complete it.

\section{Questionnaire development}


The questionnaire, described in more detail elsewhere [25], included demographic questions and source of information about NSAIDs and experiences of ADRs from NSAIDs, as well as knowledge and perception of NSAID risks. Risk perceptions were measured using five questions each representing an associated risk from NSAIDs: gastrointestinal system, cardiovascular system, renal system, blood pressure, and respiratory system. For each, a 100-mm Visual Analogue Scale (VAS) was used to measure the perception of NSAID risk, ranging from "0" (no risk) to "10" (maximum risk). Patients indicated their perception by making " $\mathrm{X}$ " on the $100-\mathrm{mm}$ VAS line. Patients' knowledge of factors which could increase the risk of adverse events from NSAIDs was measured using a list of 11 factors which did or did not have the potential to increase risk, each with three possible answers, "Yes", "No", or "Not sure". The questionnaire's validity was assessed by three experts, using the index of consistency (IOC), which was 0.97 before and 0.99 after minor revision. Pilot testing was conducted, involving 20 orthopaedic patients, to ensure readability and ease of use before data collection started.

\section{Data collection}

Every fourth patient waiting for an appointment in the out-patient clinic was approached to take part by the pharmacist researcher. Patients were asked about history of NSAID use and their medical records were accessed to confirm this. Those who had received a prescription for an NSAID for at least one month were asked to participate in the study and a questionnaire with information sheet explaining the purpose of the study was then given to patients who agreed. A total of 500 self-administered questionnaires were distributed by hand and returned directly to the researcher the same day.

\section{Statistical analysis}


Data from completed questionnaires were analysed using IBM SPSS for Windows (version 19.0). Baseline characteristics of patients were presented by means with standard deviation (mean \pm SD), or median with interquartile range (IQR) for continuous variables, and frequency and percentage for categorical variables. The perception scores were obtained by measuring the distance on the VAS line from " 0 " with the score ranging from 0 to 10 and are reported as mean $\pm \mathrm{SD}$. To assess knowledge of risk factors, the score for each of the 11 questions was counted, with each correct response being given a value of one and both "no" or "not sure" being given a value of zero. The total knowledge score range was thus 0-11 points, which was then categorised into two groups based simply on the proportion of correctly identified risk factors: low-level (correct answer $\leq$ $50 \%$, or answering 1-5 questions correctly) and high-level (correct answer $>50 \%$, or answering $>5$ questions correctly). The chi-square test and independent t-test were used to determine associations for categorical data and continuous data, respectively. All the independent variables for which an association was found were entered into a regression model. Binary logistic regression was used to assess factors influencing patients' knowledge of risk factors. Multiple linear regression was used to assess factors influencing patients' perceptions of NSAID risks.

\section{Results}

Response rate and demographic details

From the total 500 distributed questionnaires, 484 (96.8\%) were returned, with 474 being fully completed $(94.8 \%)$. The majority of respondents were female $(\mathrm{N}=337,71.1 \%)$, more than half were educated to a low level $(\mathrm{N}=278,59.5 \%)$, and the majority used an NSAID continuously or regularly $(\mathrm{N}=330,69.6 \%)$ rather than intermittently or as needed. There were $107(22.6 \%)$ with underlying cardiovascular disease, $56(11.8 \%)$ with gastrointestinal disease and $37(7.8 \%)$ with respiratory disease. Over half $(\mathrm{N}=270 ; 57.0 \%)$ were using a gastrointestinal medicine, $40(8.4 \%)$ 
a cardiovascular medicine and $8(1.7 \%)$ a respiratory medicine. The median number of comorbid diseases present was 1 (interquartile range (IQR) 0.0-1.0) and median number of concomitant medicines used was 2 (IQR 2.0-4.0). Overall, only 256 (47.1\%) claimed to have received any information about NSAID side effects.

Experiences of adverse events

Seventy-eight (16.5\%) respondents indicated that they had experienced at least one ADR from a NSAID. Patients who had experienced an ADR had more underlying diseases $(1.35 \pm 1.17)$ than those who had no $\operatorname{ADR}(0.74 \pm 0.91)(P<0.001)$. Moreover, the occurrence of ADRs was significantly higher in patients who reported regular NSAID use $(20.6 \%)$ than in patients using them intermittently (6.9\%). Those reporting an ADR also reported shorter overall duration of

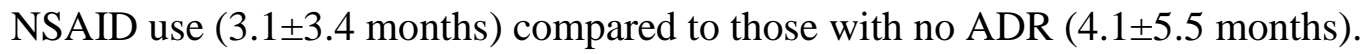

Perceptions of NSAID risks

None of the five categories of risk achieved an average scores above 5 on the VAS, indicating overall low perceptions of risk relating to NSAIDs. Patients perceived risks from NSAIDs to the renal system to be highest (mean \pm SD: median (IQR), 3.80 $\pm 2.97: 4.10(0.0-5.8)$ ), followed by gastrointestinal system $(2.93 \pm 2.92: 2.40(0.0-4.9))$, however, blood pressure $(0.82 \pm 1.84: 0.00(0.0$ $1.1))$, cardiovascular system $(0.00(0.0-0.5))$ and respiratory system $(0.48 \pm 1.54: 0.00(0.0-0.0))$ were perceived to be very low to no risk. There was a statistically significant difference in perceived risk level to the gastrointestinal system among users of non-selective and selective NSAIDs $(3.47 \pm 2.75$ vs $2.06 \pm 2.98, \mathrm{P}<0.001)$, but nor for other risks (Figure 1). However, there were no differences in perceived risk level between patients with or without experience of ADRs from NSAIDs.

(Insert Figure 1) 
Multiple linear regression was used to identify the factors affecting NSAID risk perception, but had low predictive power, being highest (19\%) for gastrointestinal risks. Regarding overall NSAID risk perception, younger patients and those who received side effect information tended to have higher perception of risk (Table 1). In relation to individual risks, older patients and selective NSAID users perceived gastrointestinal risks to be lower, whereas those who had received information about side effects or had experienced an ADR perceived risk as higher. Educational level affected perceptions of cardiovascular and respiratory risks, while receipt of information about side effects also influenced perceptions of the risk of increased blood pressure and renal problems, but not cardiovascular risk.

\section{(Insert Table 1)}

\section{Knowledge of risk factors for adverse events}

Overall awareness of factors which may increase the risks of adverse events from NSAIDs is shown in Table 2. Almost $80 \%$ knew that long-term therapy $(\mathrm{N}=140,75.3 \%)$, using a high dose $(\mathrm{N}=151,81.2 \%)$, having underlying gastrointestinal problems $(\mathrm{N}=143,76.9 \%)$ and renal disease $(\mathrm{N}=149,80.1 \%)$ could increase the risk of adverse events. However, only around half thought the elderly had an increased risk $(\mathrm{N}=98,52.7 \%)$ or that use of multiple NSAIDs was a risk factor $(\mathrm{N}=93,50.0 \%)$. There was, however, much uncertainty in particular about whether anticoagulant use $(\mathrm{N}=158,84.9 \%)$, smoking $(\mathrm{N}=104,55.9 \%)$, hypertension $(\mathrm{N}=100,53.8 \%)$ and cardiovascular disease $(\mathrm{N}=97,52.2 \%)$ presented additional risk.

(Insert Table 2)

The mean score for all 474 patients was $5.13+2.65$. From logistic regression, patients with high-level knowledge scores were more likely to have underlying disease (adjusted odds ratio; 
$\left.\mathrm{OR}_{\text {adj }} 1.64,95 \% \mathrm{CI} 1.01-2.44\right)$, and to have received side effect information ( $\mathrm{OR}_{\text {adj }} 2.02,95 \% \mathrm{CI}$ 1.35-3.03), than those with low-level knowledge scores.

(Insert Table 3)

\section{Discussion}

Overall perceptions of potential risks from NSAIDs were low among this population of Thai NSAID users, with the highest perceived risk being for gastrointestinal problems, in particular among those using non-selective NSAIDs. There may be several reasons for these findings. First, non-selective NSAIDs have been available for much longer than selective agents, thus patients may have had more opportunity to receive information about their risks. This is supported by our previous study [25], which showed that users of selective NSAIDs were less likely to receive side effect information than users of non-selective NSAID. Second, the gastro-intestinal effects of nonselective NSAIDs are widely known, , hence patients may have experienced these ADRs thus may perceive this particular risk more than others. Third, healthcare professionals may be more likely to inform patients about gastrointestinal risks from NSAIDs than other risks. Previous experience of an ADR from an NSAID and educational level were related to perceptions of risk, as was receipt of information about side effects, but this varied for different risks. Knowledge of factors with potential to increase risk was also lower than desirable, but higher among those who had received some information about side effects.

Previous work in the Slovak Republic has shown low perceptions of NSAID risk among hospital in-patients, using a similar VAS score, with risk perceived as between 3.8 and 4.7 [9]. Thus our study suggests that Thai patients perceive risk to be lower. Other work shows that patients generally perceive NSAIDs as having lower levels of risk than healthcare professional [26, 27]. Studies suggest that $56 \%$ of patients prescribed NSAIDs believe them to be safe for use [4], but 
that gastrointestinal problems are the most frequently cited potential side effects followed by kidney disease [10], similar to our findings. Provision of information about NSAID risks by physicians has been shown to be positively associated with awareness of NSAID risk among patients $[7,10]$. Only around half of the patients in our study had received any information about potential side effects, whether from physicians or pharmacists. This appeared to increased risk perception in relation to gastrointestinal system, renal system and blood pressure, but not cardiovascular or respiratory conditions. Older age and lower educational level were also potential factors influencing perceptions, and have been shown elsewhere to influence risk awareness [12, $16,28]$. Awareness of underlying problems which can contribute to or increase risks from NSAIDs is important in ensuring that patients inform health professionals about these when NSAIDs are being prescribed, which may not always be the case [29]. Perhaps most important is the need to inform health professionals, whether physicians or community pharmacists, of existing NSAID use, to reduce the risk of multiple prescription. Only half the patients in our study were aware that using multiple NSAIDs increased risk of ADRs, with $45 \%$ being uncertain. Studies suggest that multiple NSAID use is not infrequent among the general public in other countries $[3,4,8]$, however the only study on NSAID use in Thailand reported to date failed to determine whether multiple NSAIDs were used [12].

\section{Strengths and limitations}

In this study, we used the VAS approach to measuring risk perception has been used previously, enabling comparison with other work. Moreover, our study achieved a high response rate, most likely because a systematic sampling approach was used to recruit patients, as well as the questionnaires being directly distributed to patients. However, the sample size was small, and it involved orthopaedic outpatients in only one university hospital and did not involve people using 
over the counter NSAIDs. Furthermore, a large proportion of respondents were female, hence the results may not be representative of the wider Thai population. Recall bias may also have occurred, particularly for patients who had been taking NSAIDs long-term.

\section{Conclusion}

Both perception of risk and knowledge of risk factors for NSAID use were very low in Thai patients. More frequent provision of side effect information could lead to better risk perception and knowledge about NSAIDs, especially among those of older age and low education level.

\section{Acknowledgements}

We would like to thank Assist. Prof. Sermsak Sumanont and the Department of Orthopedic of Khon Kaen University for supporting this project. Additionally, we would like to thank all patients for sharing the information.

\section{Funding}

This work was supported by Khon Kaen University Integrate Multidisciplinary Research Cluster [grant number MIH-2554-Ph.D-07] and the Graduate School of Khon Kaen University [grant number 55222103].

\section{Conflict of interest statement}

All authors declare that they have no conflict of interests to declare.

\section{References}

1. Vonkeman HE, van de Laar MA. Nonsteroidal anti-inflammatory drugs: adverse effects and their prevention. Semin Arthritis Rheum. 2010;39:294-312.

2. Wehling M. Non-steroidal anti-inflammatory drug use in chronic pain conditions with special emphasis on the elderly and patients with relevant comorbidities: management and mitigation of risks and adverse effects. Eur J Clin Pharmacol. 2014;70:1159-72. 
3. Zandman-Goddard G, Langevitz P. The lack of awareness of the Israeli population regarding gastrointestinal complications from non-steroidal anti-inflammatory drugs. Harefuah. $2001 ; 140: 476-8,567,566$.

4. Wilcox CM, Cryer B, Triadafilopoulos G. Patterns of use and public perception of over-thecounter pain relievers: focus on nonsteroidal antiinflammatory drugs. J Rheumatol. 2005;32:2218-24.

5. Yilmaz H, Gürel S, Ozdemir O. Turkish patients with osteoarthritis: their awareness of the side effects of NSAIDs. Turk J Gastroenterol. 2005;16:89-92.

6. Ornbjerg LM, Andersen HB, Kryger P, Cleal B, Hetland ML. What do patients in rheumatologic care know about the risks of NSAIDs? J Clin Rheumatol. 2008;14:69-73.

7. Schmitt MR, Miller MJ, Harrison DL, Farmer KC, Allison JJ, Cobaugh DJ, et al. Communicating non-steroidal anti-inflammatory drug risks: verbal counseling, written medicine information, and patients' risk awareness. Patient Educ Couns. 2011;83:391-7.

8. Stosic R, Dunagan F, Palmer H, Fowler T, Adams I. Responsible self-medication: perceived risks and benefits of over-the-counter analgesic use. Int J Pharm Pract. 2011;19:236-45.

9. Varga Z, Kriška M, Kristová V, Petrová M. Analysis of non-steroidal anti-inflammatory drug use in hospitalized patients and perception of their risk. Interdiscip Toxicol. $2013 ; 6: 141-4$

10. van den Bogert CA, Miller MJ, Cobaugh DJ, Chen L, Allison JJ, Saag KG. Screening Questions for Nonsteroidal Anti-inflammatory Drug Risk Knowledge. J Patient Saf. 2014; doi: 10.1097/PTS.0000000000000143 
11. Matoulková $\mathrm{P}$, Dosedel M, Růzková B, Kubena A. Information and awareness concerning ibuprofen as an ingredient in over the counter analgesics: a questionnaire-based survey of residents of retirement communities. Acta Pol Pharm. 2013;70:333-8.

12. Saengcharoen W, Buasri N, Khantapokha B, Lerkiatbundit S. Public knowledge and factors associated with inappropriate analgesic use: a survey in Thailand. Int J Pharm Pract. 2016;24:22-9.

13. Turajane T, Wongbunnak R, Patcharatrakul T, Ratansumawong K, Poigampetch Y, Songpatanasilp T. Gastrointestinal and cardiovascular risk of non-selective NSAIDs and COX-2 inhibitors in elderly patients with knee osteoarthritis. J Med Assoc Thai. 2009;92:S19-26.

14. Center Health Product Vigilance. Adverse drug reactions reporting 1984-2014. Thai food and drug administration: Ministry of Public Health. 2014. http://thaihpvc.fda.moph.go.th /thaihvc/Public/News/uploads/hpvc_1_3_4_100538.pdf. Accessed 10 May 2016.

15. Albsoul-Younes AM, Jabateh SK, Abdel-Hafiz SM, Al-Safi SA. Awareness and frequency of potential side effects on nonsteroidal anti-inflammatory drugs among the Jordanian patient population. Saudi Med J. 2004;25(7):907-11.

16. Miller MJ, Schmitt MR, Allison JJ, Cobaugh DJ, Ray MN, Saag KG. The role of health literacy and written medicine information in nonsteroidal antiinflammatory drug risk awareness. Ann Pharmacother. 2010;44:274-84.

17. Lanas A, Garcia-Tell G, Armada B, Oteo-Alvaro A. Prescription patterns and appropriateness of NSAID therapy according to gastrointestinal risk and cardiovascular history in patients with diagnoses of osteoarthritis. BMC Med. 2011;9:38. 
18. Stevenson FA, Cox K, Britten N, Dundar Y. A systematic review of the research on communication between patients and health care professionals about medicines: the consequences for concordance. Health Expect. 2004;7:235-45.

19. Sheard C, Garrud P. Evaluation of generic patient information: effects on health outcomes, knowledge and satisfaction. Patient Educ Couns. 2006;61:43-7.

20. Grime J, Blenkinsopp A, Raynor DK, Pollock K, Knapp P. The role and value of written information for patients about individual medicines: a systematic review. Health Expect. 2007;10:286-98.

21. Mcneal TM, Colbert CY, Cable C, Mirkes CR, Lubowinski JG, Myers JD. Patients' attention to and understanding of adverse drug reaction warnings. Patient Intelligence. 2010;2:59-68.

22. Wilson FL, Mood D, Nordstrom CK. The influence of easy-to-read pamphlets about selfcare management of radiation side effects on patients' knowledge. Oncol Nurs Forum. 2010;37:774-81.

23. Mahler C, Hermann K, Jank S, Haefeli WE, Szecsenyi J. Can a feedback report and training session on medication counseling for general practitioners improve patient satisfaction with information on medicines? Patient Prefer Adherence. 2012;6:179-86.

24. Phueanpinit P, Pongwecharak J, Krska J, Jarernsiripornkul N. Medicine information leaflets for non-steroidal anti-inflammatory drugs in Thailand. Int J Clin Pharm. 2016;38:25-9.

25. Jarernsiripornkul N, Phueanpinit P, Pongwecharak J, Krska J. Experiences of and attitudes towards receiving information about non-steroidal anti-inflammatory drugs: a crosssectional survey of patients in Thailand. Expert Opin Drug Saf. 2016;15:417-26. 
26. Bongard V, Ménard-Taché S, Bagheri H, Kabiri K, Lapeyre-Mestre M, Montastruc JL. Perception of the risk of adverse drug reactions: differences between health professionals and non health professionals. Br J Clin Pharmacol. 2002;54:433-6.

27. Cullen G, Kelly E, Murray FE. Patients' knowledge of adverse reactions to current medications. Br J Clin Pharmacol. 2006;62:232-6.

28. Fry RB, Ray MN, Cobaugh DJ, Weissman NW, Kiefe CI, Shewchuk RM, et al. Racial/ethnic disparities in patient-reported nonsteroidal antiinflammatory drug (NSAID) risk awareness, patient-doctor NSAID risk communication, and NSAID risk behavior. Arthritis Rheum. 2007;57:1539-45.

29. Fourrier-Réglat A, Lacoin L, Pariente A, Lassalle R, Robinson P, Droz-Perroteau C, et al. When patients report diseases that prescribers seem unaware of: discordance between patient and physician reporting of risk-related previous history in NSAID users from the CADEUS study. Clin Pharmacol Ther. 2010;88:668-75. 


\section{Appendix}

Table 1 Factors associated with patients' perception on NSAID risks (Linear regression analysis)

\begin{tabular}{|c|c|c|c|c|c|c|c|}
\hline \multirow{2}{*}{ Factors } & \multirow{2}{*}{ b } & \multirow{2}{*}{$\mathbf{S E}_{\mathbf{b}}$} & \multirow{2}{*}{$\beta$} & \multirow{2}{*}{$\mathbf{t}$} & \multicolumn{2}{|c|}{ 95\% Confidence Interval } & \multirow{2}{*}{$p$-value } \\
\hline & & & & & Lower & Upper & \\
\hline \multicolumn{8}{|l|}{ Risks to the gastrointestinal system ${ }^{a}$} \\
\hline Age & -0.49 & 0.18 & -0.11 & -2.68 & -0.85 & -0.13 & 0.008 \\
\hline Group of NSAID used & -0.95 & 0.26 & -0.16 & -3.69 & -1.45 & -0.44 & $<0.001$ \\
\hline Receive side effect information & 1.93 & 0.26 & 0.32 & 7.42 & 1.43 & 2.44 & $<0.001$ \\
\hline \multirow[t]{2}{*}{ ADR experience } & 0.95 & 0.33 & 0.12 & 2.88 & 0.30 & 1.59 & 0.004 \\
\hline & \multicolumn{7}{|c|}{$\begin{array}{c}\text { Constant 2.98; } \mathrm{SE}_{\text {est }}= \pm 2.63 \\
\mathrm{R}=0.44 ; \text { Adjusted } \mathrm{R}^{2}=0.19 ; \mathrm{F}=28.27 ; p \text {-value }=<0.001\end{array}$} \\
\hline \multicolumn{8}{|l|}{ Risks to the cardiovascular system ${ }^{b}$} \\
\hline Educational level & 0.46 & 0.17 & 0.13 & 2.73 & 0.13 & 0.79 & 0.007 \\
\hline \multirow[t]{2}{*}{ Receive side effect information } & 0.23 & 0.17 & 0.06 & 1.33 & -0.11 & 0.56 & NS \\
\hline & \multicolumn{7}{|c|}{$\begin{array}{c}\text { Constant } 0.46 ; \mathrm{SE}_{\text {est }}= \pm 1.71 \\
\mathrm{R}=0.14 ; \text { Adjusted } \mathrm{R}^{2}=0.02 ; \mathrm{F}=5.01 ; p \text {-value }=0.007\end{array}$} \\
\hline \multicolumn{8}{|l|}{ Risks to the renal system $^{c}$} \\
\hline Gender & 0.60 & 0.30 & 0.09 & 2.02 & 0.02 & 1.19 & 0.04 \\
\hline Receive side effect information & 1.09 & 0.28 & 0.18 & 3.87 & 0.53 & 1.63 & $<0.001$ \\
\hline \multirow{2}{*}{ Regularity of NSAIDs use } & 0.30 & 0.30 & 0.05 & 1.02 & -0.28 & 0.89 & NS \\
\hline & \multicolumn{7}{|c|}{$\begin{array}{c}\text { Constant 2.87; } \mathrm{SE}_{\text {est }}= \pm 2.91 \\
\mathrm{R}=0.21 ; \text { Adjusted } \mathrm{R}^{2}=0.04 ; \mathrm{F}=6.87 ; p \text {-value }=<0.001\end{array}$} \\
\hline \multicolumn{8}{|l|}{ Risk to blood pressure $^{\mathrm{d}}$} \\
\hline Receive side effect information & 0.52 & 0.17 & 0.14 & 2.99 & 0.18 & 0.86 & 0.003 \\
\hline \multirow[t]{2}{*}{ ADR experience } & 0.29 & 0.23 & 0.06 & 1.28 & -0.16 & 0.75 & NS \\
\hline & \multicolumn{7}{|c|}{$\begin{array}{c}\text { Constant } 0.57 ; \mathrm{SE}_{\text {est }}= \pm 1.816 \\
\mathrm{R}=0.146 ; \text { Adjusted } \mathrm{R}^{2}=0.017 ; \mathrm{F}=5.050 ; p \text {-value }=0.007\end{array}$} \\
\hline \multicolumn{8}{|l|}{ Risks to the respiratory system ${ }^{\mathrm{e}}$} \\
\hline Gender & 0.33 & 0.16 & 0.10 & 2.02 & 0.01 & 0.65 & 0.04 \\
\hline Age & -0.14 & 0.11 & -0.06 & -1.24 & -0.36 & 0.08 & NS \\
\hline Educational level & 0.33 & 0.16 & 0.10 & 2.09 & 0.02 & 0.64 & 0.03 \\
\hline \multirow[t]{2}{*}{ Receive side effect information } & 0.23 & 0.15 & 0.07 & 1.55 & -0.06 & 0.53 & NS \\
\hline & \multicolumn{7}{|c|}{$\begin{array}{c}\text { Constant } 0.22 ; \mathrm{SE}_{\text {est }}= \pm 1.54 \\
\mathrm{R}=0.17 ; \text { Adjusted } \mathrm{R}^{2}=0.02 ; \mathrm{F}=3.47 ; p \text {-value }=0.008\end{array}$} \\
\hline \multirow{4}{*}{$\begin{array}{l}\text { Overall NSAID risk perception } \\
\text { Age } \\
\text { Receive side effect information }\end{array}$} & & & & & & & \\
\hline & -1.046 & .518 & -.094 & -2.021 & -2.064 & -.029 & 0.044 \\
\hline & 4.281 & .719 & .277 & 5.951 & 2.867 & 5.695 & $<0.001$ \\
\hline & \multicolumn{7}{|c|}{$\begin{array}{r}\text { Constant } 8.475 ; \mathrm{SE}_{\text {est }}= \pm 7.16 \\
\text { Adjusted } \mathrm{R}^{2}=0.092 ; \mathrm{F}=23.104 ;\end{array}$} \\
\hline
\end{tabular}

Notes:

b denotes the variable estimate

$\mathrm{SE}_{\mathrm{b}}$ denotes the standard error of the variable estimate

$\beta \quad$ denotes the standardized estimate

$\mathrm{t}$ denotes the $\mathrm{t}-\mathrm{value}$ 
NS denotes non-significant

a Adjusted for age, health insurance, herb/supplement, group of NSAIDs, concomitant drugs, comorbid diseases, duration of use, regularity of NSAID use, receive side effect information, and ADR experience

b Adjusted for age, educational level, occupation, income, receive side effect information, and ADR experience

c Adjusted for gender, regularity of NSAID use, receive side effect information, and ADR experience

d Adjusted for age, educational level, concomitant drugs, regularity of NSAID use, receive side effect information, and ADR experience

e Adjusted for gender, age, educational level, income, herb/supplement, regularity of NSAID use, receive side effect information, and ADR experience

Table 2 Patients' knowledge concerning risk factors of NSAIDs 


\begin{tabular}{lccc}
\hline \multicolumn{1}{c}{ Potential risk factors for NSAID-related ADRs } & \multicolumn{2}{c}{ Number of patients (\%) } \\
\cline { 2 - 4 } & Know & Not know & Not sure \\
\hline Using a high dose of NSAIDs & $151(81.2)$ & $6(3.2)$ & $29(15.6)$ \\
Using NSAIDs in patient with renal disease & $149(80.1)$ & $5(2.7)$ & $32(17.2)$ \\
Using NSAIDs in patient with gastrointestinal ulcer or bleeding & $143(76.9)$ & $2(1.1)$ & $41(22.0)$ \\
history & & & $40(21.5)$ \\
Long-term use of NSAIDs & $140(75.3)$ & $6(3.2)$ & $42(44.1)$ \\
Using NSAIDs in elderly & $98(52.7)$ & $6(3.2)$ & $84(45.2)$ \\
Multiple NSAIDs use & $93(50.0)$ & $9(4.8)$ & $89(47.8)$ \\
Drinking alcohol during NSAIDs therapy & $86(46.2)$ & $11(5.9)$ & $89(52.2)$ \\
Using NSAIDs in patient with cardiovascular disease & $72(38.7)$ & $17(9.1)$ & $97(84)$ \\
Using NSAIDs in patient with hypertension & $63(33.9)$ & $23(12.4)$ & $100(53.8)$ \\
Smoking during NSAIDs therapy & $48(25.8)$ & $34(18.3)$ & $104(55.9)$ \\
Using NSAIDs in patient taking anticoagulants & $22(11.8)$ & $6(3.2)$ & $158(84.9)$ \\
\hline
\end{tabular}

Table 3 Factors associated with patients' knowledge on NSAID risk factors (Logistic regression

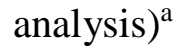




\begin{tabular}{|c|c|c|c|c|c|c|}
\hline \multirow{3}{*}{ Factors } & \multirow{2}{*}{\multicolumn{2}{|c|}{$\begin{array}{l}\text { No. of patients with correct } \\
\qquad \operatorname{answers~}^{\mathrm{b}}(\%)\end{array}$}} & \multirow{3}{*}{$\begin{array}{c}\text { Adjusted } \\
\text { OR }\end{array}$} & \multirow{2}{*}{\multicolumn{2}{|c|}{ 95\% C.I. }} & \multirow{3}{*}{$p$-value } \\
\hline & & & & & & \\
\hline & $\leq 50 \%$ of all & $>50 \%$ of all & & Lower & Upper & \\
\hline \multicolumn{7}{|l|}{ Underlying diseases } \\
\hline Not have & $133(51.6)$ & $95(44.0)$ & 1 & & & \\
\hline Have & $125(48.4)$ & $121(56.0)$ & 1.64 & 1.10 & 2.44 & 0.02 \\
\hline \multicolumn{7}{|l|}{ Receive side effect information } \\
\hline No & $176(68.2)$ & $112(51.9)$ & 1 & & & \\
\hline Yes & $82(31.8)$ & $104(48.1)$ & 2.02 & 1.35 & 3.03 & 0.001 \\
\hline Concomitant drugs (Mean \pm S.D.) & $2.91 \pm 1.75$ & $2.65 \pm 1.68$ & 0.89 & 0.78 & 1.00 & NS \\
\hline
\end{tabular}
Notes:

NS denotes not significant

a Variables included in the analysis were education level, occupations, income, underlying disease, concomitant drugs, duration of use, regularity of NSAID use, receive side effect information, and ADR experience

b Correct answers were defined as positive knowledge ("yes" response) of potential risk factors 
Figure 1 Mean ( \pm S.D.) visual analog scale of perception on NSAID risks classified by type of NSAIDs

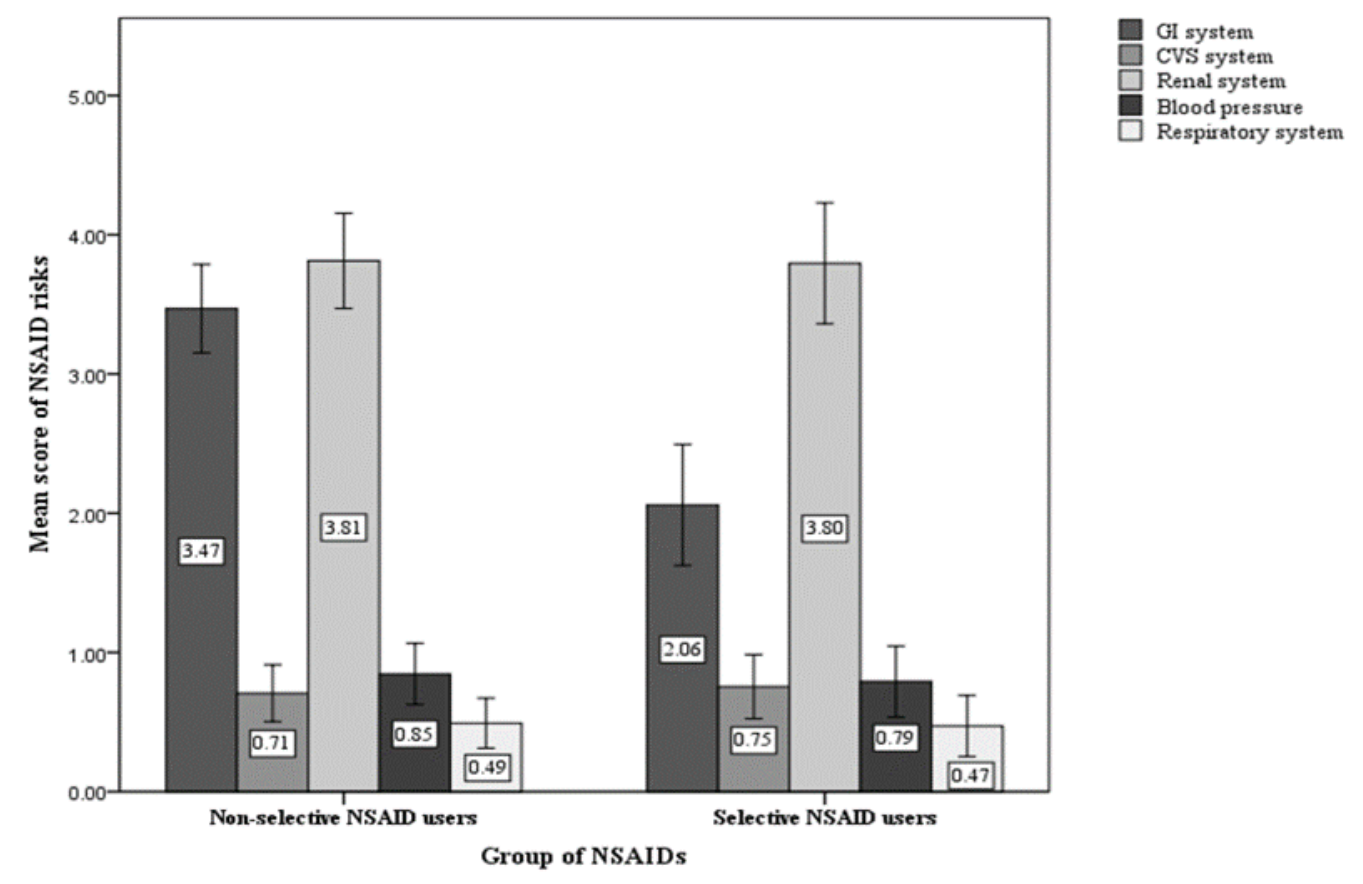

